\title{
Novas perspectivas para avaliação em psicologia do esporte e do exercício físico
}

\author{
Talita Fernanda da Silva, Gabriela Fabbro Spadari ${ }^{1}$ \\ Pontifícia Universidade Católica de Campinas, Campinas-SP, Brasil
}

O livro Novas perspectivas para avaliação em psicologia do esporte e do exercício físico, de autoria de Evandro Morais Peixoto, Tatiana de Cássia Nakano e Marcos Alencar Abaide Balbinotti, compõe um conjunto de textos de estudiosos nacionais e internacionais que buscam discutir e refletir acerca das ferramentas e dos procedimentos de avaliação psicológica em contexto esportivo e do exercício físico. Assim, a obra busca abordar questões relacionadas à avaliação psicológica nesse contexto específico, tendo como partida discussões a respeito dos construtos relevantes para avaliação de atletas em diferentes modalidades esportivas. $\mathrm{O}$ presente trabalho teve como foco as populações de atletas que enfrentam transições na carreira esportiva, os participantes de projetos sociais e educacionais e até mesmo os idosos ingressantes em programas de atividades físicas. Além disso, ele preambula na amplitude de pesquisas na área, ressaltando as lacunas ainda existentes, bem como destacando a importância do estímulo à investigação voltada para avaliação psicológica na área da psicologia do esporte.

Com isso, a obra apresenta uma diversidade de conhecimentos e de possibilidades organizada em 11 capítulos. Os dois primeiros abordam a temática de maneira global, ressaltando ao leitor a necessidade de práticas de avaliação psicológica na visão esportiva. Posteriormente, cada um desses capítulos discute um construto específico, trazendo então, para a conclusão, uma reflexão no que concerne aos motivos e à importância da avaliação em tal contexto.

O primeiro capítulo, denominado "A necessidade de práticas de avaliação psicológica no contexto desportivo", de autoria de José Maria Montiel, Daniel Bartholomeu e Karina Costa, em primeiro lugar retoma a história da avaliação psicológica, e, no segundo momento, enfatiza o contexto desportivo, estabelecendo seus problemas e questões direcionadas à aplicação da avaliação psicológica nesse sentido. Sugere, ainda, soluções acerca da inserção de programas de psicologia aplicada ao esporte.
No segundo capítulo, os autores Ivan Sant'Ana Rabelo, Luciana Ferreira Angelo, Gabriela de Carvalho Monteiro Gonçalves e Katia Rubio contextualizam as mais variadas práticas de avaliação psicológica, intitulando o capítulo de "Diferentes práticas da avaliação psicológica no contexto desportivo". Os autores primeiramente discutem a respeito da avaliação psicológica, apresentando, em seguida, procedimentos utilizados para investigar o nível de desenvolvimento das características de cunho psicológico que contribuem para a prática esportiva, com o intuito de qualificar e quantificar estados emocionais. Tais procedimentos consistem na utilização de entrevistas, escalas, questionários e até mesmo testes, possibilitando, portanto, psicodiagnósticos das características cognitivas e emocionais de atletas, auxiliando no desenvolvimento pessoal deles. Ademais, os autores abordam nesse capítulo a temática da dor, pois ela faz parte desse universo, e muitas vezes é interpretada de forma errônea, levando a sofrimentos extremos e até mesmo lesões. Por fim, discute-se a importância da verbalização da história oral, com base em um projeto de pesquisa do Grupo de Estudos Olímpicos (GEO), além do desenvolvimento de medidas para a avaliação de características cognitivas, sociais, emocionais e de personalidade.

Depois, o capítulo "Eficácia adaptativa: proposta de avaliação da personalidade em psicologia do esporte", de Evandro Morais Peixoto, Elisa Medici Pizão Yoshida e Tatiana de Cássia Nakano, tem como objetivo discutir os desafios enfrentados por estudiosos e profissionais práticos da psicologia do esporte, por conta da necessidade de avaliação da personalidade de atletas brasileiros. Assim, propõe-se uma nova compreensão sobre a avaliação da personalidade de atletas brasileiros de alto rendimento, voltando-se ainda para o processo adaptativo dessa população, e apresentando a Escala Diagnóstica Adaptativa Operacionalizada para Atletas (EDAO-AR-A) para avaliação, bem como a teoria que a fundamenta. 
O quarto capítulo, chamado de "Investigando o conceito de resiliência: considerações metodológicas e aplicações no contexto esportivo", de Simone Meyer Sanches, inicialmente apresenta o conceito de resiliência de maneira geral e, posteriormente, aplicado no contexto esportivo, uma vez que a capacidade de resiliência pode ser uma habilidade psicológica de extrema relevância no esporte de alto rendimento. Com base nisso, a autora discorre a respeito dos fatores de risco, fatores de proteção, aplicação de intervenção focada em resiliência em projetos sociais esportivos e em esporte de alto rendimento. Também desenvolve uma revisão das pesquisas na área da atividade física. Finaliza seu texto apontando os obstáculos encontrados para a prática do psicólogo do esporte.

Adiante, o quinto capítulo, denominado de "Inveja no esporte: teoria e avaliação desse lado escuro e não declarado da competição esportiva", de Emmanuel Habimana, Violaine Denoyerss, Line Massé, Daniela Wiethaeuper, Marcos Balbinotti e Carlos Balbinotti, tem por objetivo discutir a temática da inveja no esporte,. Com isso, apresenta o tema sob dois olhares: a inveja moral e a inveja psicanalítica, e a sua relação com o ciúme. Além disso, os autores destacam e descrevem a expressão da inveja no esporte, sua origem e sua forma de avaliação.

Em seguida, o capítulo nomeado "Avaliação da agressividade de atletas por meio da TRI: otimizando escalas e estabelecendo pontos de corte para classificação de atletas”, de Daniel Bartholomeu, José Maria Montiel, Afonso Antonio Machado e Karina Costa, objetiva discutir a agressividade em atletas. Para isso, os autores apresentam o conceito e sua aplicação no esporte e, posteriormente, buscam refletir a respeito da lacuna existente quando se trata de instrumentos para avaliação psicológica de maneira específica para o esporte. Fundamentados nisso, exibem estudos de evidências de validade e normas para a Escala de Agressividade em Competição, baseados na Teoria de Resposta ao Item (TRI).

O sétimo capítulo, intitulado "Compreendendo as transições na carreira esportiva”, de autoria de Evandro Morais Peixoto, Giovanna Corte Honda e Bartira Pereira Palma, avalia a transição de categoria juvenil para adulto. Essa avaliação é feita por meio do Questionário de Monitoramento de Transição. O interesse volta-se para esse tema, pois se sabe-se a importância das transições no âmbito esportivo, uma vez que o atleta passa por diferentes fases desde o início da carreira esportiva até sua aposentadoria. O Questionário de Monitoramento de Transição, por sua vez, é discutido no capítulo, baseando-se em três modelos teóricos - Modelo de Descrição Analítico, Modelo de Desenvolvimento das Transições Enfrentadas pelos Atletas e Modelo de Transição da Carreira Atlética —, com o intuito de compreender as possíveis transições na carreira esportiva. Posteriormente, os autores explanam sobre o Modelo de Desenvolvimento das Transições Enfrentadas pelos Atletas e as etapas influenciadoras.
No oitavo capítulo, "Avaliação psicológica voltada à população de paratletas: revisão de estudos", Carolina Rosa Campos, Rauni José Roama Alves e Tatiana de Cássia Nakano abordam a avaliação psicológica de forma ampla, bem como focada às populações específicas. Primeiramente, os autores debatem sobre a importância da avaliação psicológica e suas características, como a utilização de testes psicológicos válidos. Em seguida, discute-se a escassez de materiais apropriados e validados para determinadas áreas, como a esportiva e as populações minoritárias, tais como indivíduos superdotados, deficientes, idosos e até mesmo atletas de alto rendimento e paratletas. Em seguida, são apresentadas algumas considerações acerca da avaliação psicológica de atletas, bem como suas características e especificidades (histórico do desenvolvimento da área, principais construtos investigados, questionamentos presentes). Também são exibidos estudos internacionais de avaliação psicológica de paratletas, os quais contemplam a relevância dos estudos voltados a essa população, assim como revisão de literatura científica nacional e internacional na temática.

Em seguida, o capítulo "Avaliação psicológica na dança: instrumentos e procedimentos", de Andressa Melina Becker da Silva e Sônia Regina Fiorim Enumo, traz a contextualização a respeito da dança e as possíveis concomitâncias com o esporte. Isso porque a dança não é considerada uma modalidade esportiva, mas se encontra fundamentada nos princípios da psicologia do esporte e da atividade física, por exigir demandas físicas e psicológicas semelhantes, além de ocorrer em um contexto de competição individual e entre equipes. Outro ponto discutido pelas autoras é a questão da avaliação psicológica na área esportiva, tida como de grande importância, porém o que se observa é a carência de instrumentos que avaliem constructos psicológicos em atletas, especialmente bailarinos. Diante desse quadro, p capítulo objetiva discutir as dificuldades encontradas no acesso a instrumentos específicos de avaliação psicológica para bailarinos, levando em conta as especificidades da modalidade, bem como apresentar possíveis soluções e testes que estão sendo validados para essa população. Além disso, discutiu-se acerca da importância da avaliação psicofisiológica, que pode ser aplicada na área da dança e do esporte.

O décimo capítulo, intitulado "Avaliação cognitiva como parte da avaliação global do idoso praticante de atividade física", de Renata Eloah de Lucena FerrettiRebustini, Flávio Rebustini e Marcos Alencar Abaide Balbinotti, traz uma visão geral do envelhecimento e a ligação de envelhecimento com atividade física, pois ambas estão atreladas, uma vez que a prática regular de atividade física beneficia as saúdes física e mental dessa população. Em seguida, os autores debatem sobre a avaliação global do idoso, um processo sistematizado envolvendo a avaliação de todas as dimensões que podem interferir na saúde do idoso. Posteriormente, envelhecimento e cognição são discutidos no presente capítulo, bem como sua 
relação e importância na avaliação cognitiva do idoso e os instrumentos de avaliação utilizados.

O último capítulo, denominado de "Para que avaliar num contexto esportivo caótico?", de autoria de Afonso Antônio Machado, busca discorrer a respeito da avaliação psicológica e sua relação com a psicologia do esporte e a mídia. Além disso, o autor destaca alguns questionamentos e indica necessidades de uma avaliação contextualizada e contemporânea.

De modo geral, considerando a relevância da temática, a obra visa preencher uma importante lacuna na literatura brasileira em relação à falta de informações a respeito da avaliação em psicologia do esporte, bem como contribuir com dados para outras áreas do conhecimento que estudam e se interessam pela temática do esporte, como educação física, ciências da saúde, entre outras. O livro expõe questões teóricas e práticas no que concerne ao contexto esportivo organizadas de maneira que elas não apresentam apenas uma visão de autores brasileiros, mas também internacionais. Ainda, a obra possui linguagem clara e compreensível, acessível aos profissionais, pesquisadores e estudantes da área, além dos leitores que se interessam pelo tema e que buscam encontrar referências teóricas e fontes de informação.

Por fim, acredita-se que o material possa incentivar e impulsionar a produção de futuras pesquisas na área, visto que se carece de ampliação teórica e prática, a fim de impactar a construção de ferramentas e procedimentos de avaliação psicológica em contexto esportivo e do exercício físico. Pode-se afirmar que a obra atende aos objetivos de transmitir conhecimento e ser uma referência para os profissionais, principalmente aos voltados à avaliação psicológica de atletas e à qualidade de vida daqueles que estão inseridos no contexto esportivo.

\section{Referências}

Peixoto, E. M., Nakano, T. C., \& Balbinotti, M. A. A. (org). (2016). Novas perspectivas para avaliação em psicologia do esporte e do exercício físico. Curitiba: Editora CRV.

\section{Sobre as autoras}

Talita Fernanda Silva é Psicologa em instituicao de alta complexidade, realiza ações com crianças, adolescentes e famílias. Docente em disciplinas de Pos Graduação. Trabalhos voltados p area de Avaliação Psicológica e Educação.

Gabriela Fabbro Spadari é Psicóloga, Doutoranda em Avaliação Psicológica pela Puc-Campinas, bolsista Capes. Mestra em Psicologia como Profissão e Ciência e Especialista em Psicologia Clinica Cognitivo Comportamental. Experiência nas áreas de Avaliação Psicológica, Clínica e Organizacional. 